\title{
Application of Collaborative Design Strategy on Redesign of the Cordless Household Vacuum Cleaner
}

\author{
Shih-Wen Hsiao \\ Department of Industrial Design \\ National Cheng Kung University \\ Tainan, Taiwan \\ swhsiao@mail.ncku.edu.tw
}

\author{
Ting-An Yeh \\ Department of Industrial Design \\ National Cheng Kung University \\ Tainan, Taiwan \\ ann012083@gmail.com
}

\begin{abstract}
Nowadays, the vacuum cleaner is a quite convenient cleaning tool which is cable or cordless, industrial or household, and even equipped with a microprocessor that automatically clean the floor at home. Because the cordless vacuum cleaner is not limited to the cord and more convenient to clean around the house, it gradually becomes popular. However, the battery-powered vacuum cleaner still has to be improved. This paper presents a method to set up the market position of the product through the image scale and subsequently by $5 \mathrm{~W} 1 \mathrm{H}$ and tree diagram method, and clarifies the problems and the direction of the design goals. The following step, according to Morphological Analysis and Finite Structure method (FSM), arranges the positions of the major components of the product, and shapes the forms for developing the possible alternatives. Then, it is the most suitable for the consumers that using PUGH several times to choose the final solution. Eventually, using the sketches and computer-aided design (CAD) software turn the concept into reality. This study provides an approach to visualize the black-box design process, additionally showing that this design process is not only to improve the presented the disadvantages of the vacuum cleaners but also to reach the consumer demands. Application the cordless vacuum in the design process, changing the original design process including subjective awareness of the designers, results in the optimal alternative proved by lots of data and analysis, showing that the method proposed is applied to other products as well.
\end{abstract}

Keywords-collaborative design, cordless vacuum cleaner, morphological analysis, FSM, PUGH

\section{INTRODUCTION}

The product design requires a lot of consideration factors: except for the shape, color, and aesthetic feeling, the number and the position of components, product function, the production cost, assembly efficiency, storage, shipping, and so on will affect the form design. Designers throughout the design process, determines not only the appearance, but also the dimensions and function in order to make the products reach the market demands and be able to manufacture, meanwhile, satisfying the designer's ideal. It is so many elements to consider that designers need a set of objective criteria aiding design. In addition, with the rapid development of the technology, the global industry has entered industry 4.0. Because the production and the publish of the new products become faster and faster, the time to develop and design a product has been shortened. As a result, there are a variety of design methods have been proposed, such as morphological analysis, analytic hierarchy Process (AHP), PUGH, and so on, which provide designers an easy way to make decisions based on the objective data and been more persuasive. Also, it can improve the traditional design method that the designers subjectively determine the final product alternative [1]

\section{BACKGROUNDS}

\section{A. Image Scale}

The results from evaluation the existing products in the market between two elements will be indicated in the $\mathrm{X}$-axis and Y-axis, which represent different meaning respectively. The plot shows clearly the difference between the products. According to various demands, the meaning of axis can be arbitrarily set. Finally, select the position that the product is desired to achieve.

\section{B. $5 W 1 H$}

"Five Ws" was proposed by the American political scientist, Harold Lasswell, who presented a published paper showing the five elements of the communication process in 1948 [2]. After the continuous application and improvement of other researchers, the concept gradually formed now known as the "five Ws and one $\mathrm{H}(5 \mathrm{~W} 1 \mathrm{H})$ ". 5W1H analysis, also known as six Ws analysis, is a way of thinking, or a design method. The operation is from reason (WHY), things (WHAT), locations (WHERE), time (WHEN), People (WHO), the method (HOW) six aspects to consider and ask questions in development. It seems to be a simple communication and thinking method but it can not only deepen the content comprehensively, but also clarify the issues.

\section{Morphological Analysis}

Morphological analysis, also known as general morphological analysis, is a kind of development method proposed by Fritz Zwicky in 1967 [3], being used to explore the solutions of the multidimensional and complex nonquantitative problems. This method simplifies the analysis of the problem. Morphological analysis contains parameters and components [4]. The parameters show the importance of 
certain characteristics of the product, while the components are the methods that can be realized. The parameters, abstract and extensive, do not have actual reference samples, and rarely have the essential characteristics, which may be an adjective or a problem. Every parameter illustrates a series of similar components or procedures, and however the elements, which are specific, can be established every element suitable for their property.

\section{Finite Structure Method}

Finite structure method (FSM) is a basic approach of form development in order to reach the main and minor product functions and under the limited numbers of the alternatives, vary the structure in pursuit of a possible form divergence. The product form, due to the differences of main and minor, becomes various. Discussing in the system concept, the main function of the product can be decomposed into a combination of several sub-functions and define the element that reaches sub-function as a component, which influences the form design. As a result, every product can use this concept to combine elements of the sub-function which is limited under a certain number to help design divergence [5]. In general, variables include the divergence of the position, the number of three-dimensional level, and the standard size. Although it is enough to solve most of the problems, there are still shortcomings depended on other design methods to improve.

\section{E. Decision-matrix method (PUGH method)}

Decision-matrix method or PUGH method is invented by Stuart Pugh [6], which is a qualitative technique for ranking multidimensional options. It is often used in engineering and design decisions, investment, vendor, product selection, etc. The basic decision matrix includes the establishment of a set of standard options that are scored and the total scores are ranked in the unweighted case. The operation of the weighted decision matrix is in common with the basic, but lead into the order of importance, weights [7]. The final scores can reflect the importance of the standards. The more important criteria should be given higher weights. The advantages of the decision-matrix are objective and sensitivity studies can be carried out.

The basic approach is to integrate the design concept to meet theconsumers demands to scores, and compare the relative points to select the best design. Its process has five steps, as shown in Table 1:

TABLE 1 THE DECISION-MATRIX STEP TABLE OF PUGH METHOD

\begin{tabular}{|l|l|l|}
\hline & $\begin{array}{l}\text { List the alternatives } \\
\text { (Step 3) }\end{array}$ & \\
\hline $\begin{array}{l}\text { List the comparison } \\
\text { elements (step 1) }\end{array}$ & Score (Step 4) & Weights (Step 2) \\
\hline
\end{tabular}

\section{CASE StUdy}

The vacuum cleaner types are various. According to their drives, the vacuum cleaner can be divided into $\mathrm{AC}, \mathrm{DC}$ and $\mathrm{AC} / \mathrm{DC}$ two driven ways, while based on the structure, it can be classified into the following categories [8], shown in Figure 1:

- Upright vacuum cleaner: shapes are mostly cuboid or cylindrical, divided into two parts: upper and lower parts. The upper part containing the motor is power part, and the lower part is the dirt bin.

- Canister vacuum cleaner: the shapes are cuboid. There are two parts, the front of which is dirt bin, and the rear part contains the motor.

- Handheld vacuum cleaner: its power is generally $250 \mathrm{~W}$ or below, having 4 forms: first, backpack, small bulk and power. When using, carry it on the shoulder. Second, upright, shaped like rod and small power. The upper part is the handle, and the lower part is the head. Third, handheld, smaller bulk and power, can directly be gripped in the hand. Last, micro type is batterypowered, smallest bulk, small power and used for cleaning clothes, equipment, etc.

Fig. 1. Classification of the vacuum cleaner.

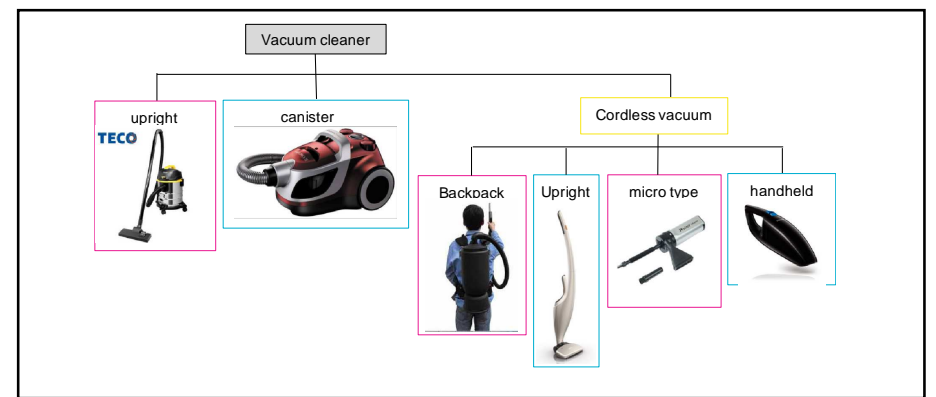

F. Data Collection and Investigation

The data are collected by the pre-operation of the pipeline, and analyzed the investigation in order to understand the function and structure of the product and the current product market. Then determine the direction of the main design goals. By going to the store to investigate the function, features, specifications, appearance, etc. of the cordless vacuum cleaner latest products among the major brands, understand the current technological development, and ask the sellers about the sales and the consumers' preferences. Collect information on Internet to know the advantages and disadvantages after using a cordless vacuum cleaner. Finally, use questionnaire to ask people who have experience of using the vacuum cleaner, deeply understanding the using of the vacuum cleaner, and the general problems and difficulties in the use of the vacuum cleaner, people may encounter. In addition, looking for information on Internet and books to understand how the vacuum cleaner works. The study investigates the exsting products on the market, shown as Table 2.

Fig. 2. Images scale analysis of the existing products

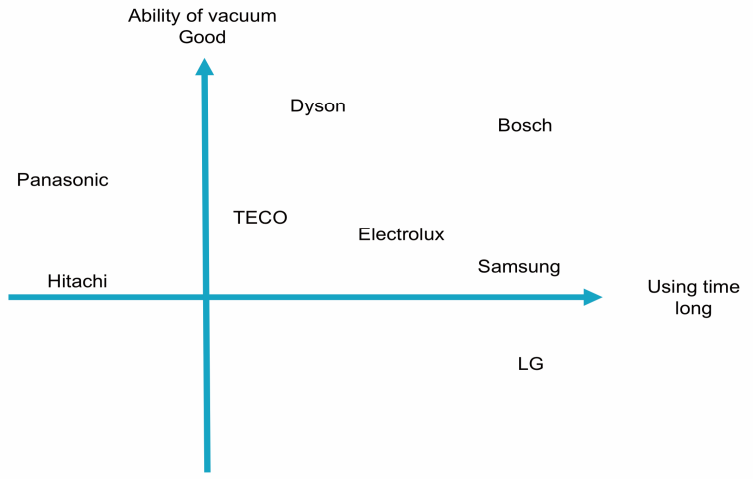


TABLE 2 THE INVESTIGATION OF THE EXISTING PRODUCTS

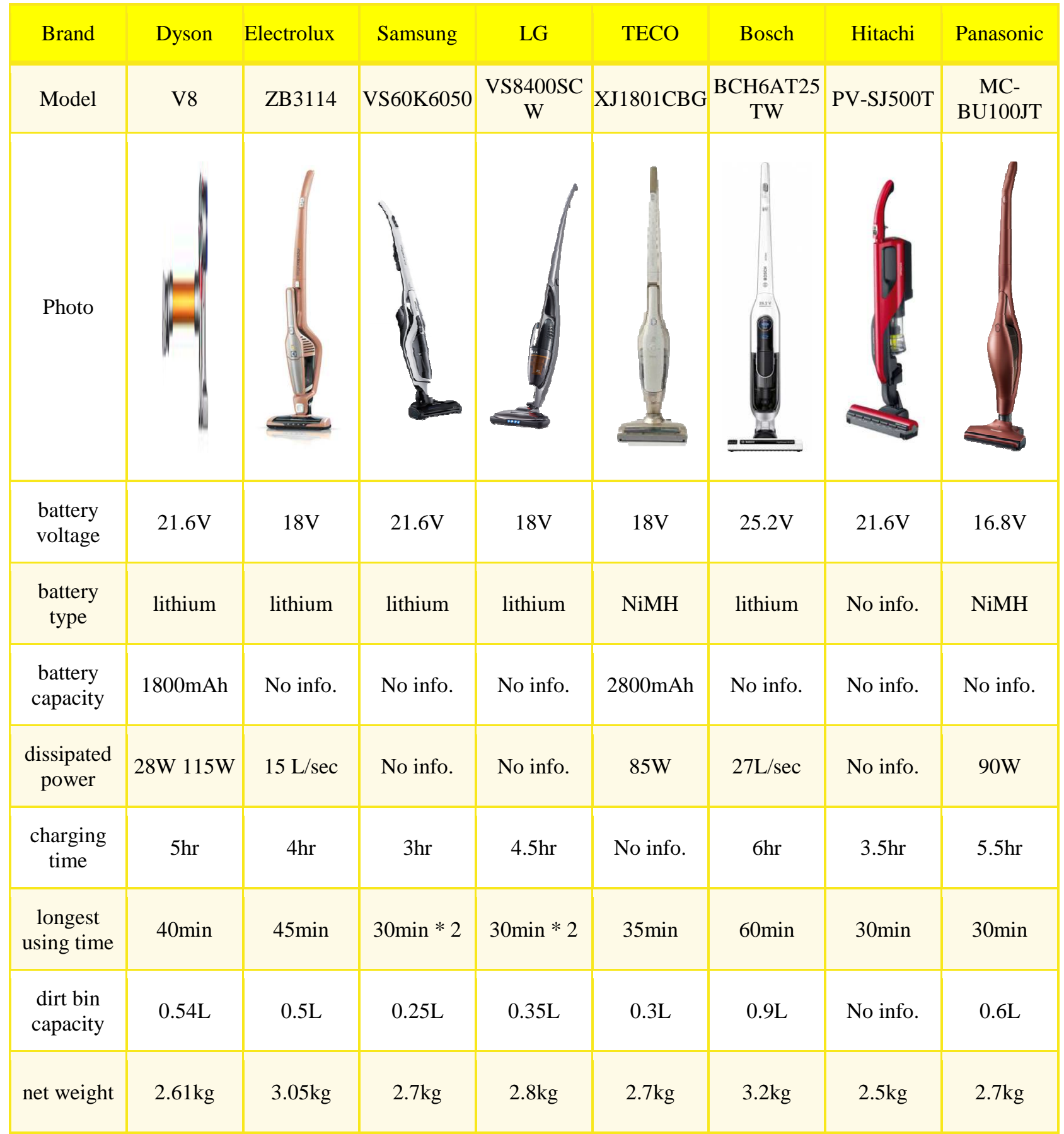

Depending on the product at the position of the image scale, it is able to understand and observe the difference of the existing products. The complete information of the products' pictures reserved here is to develop the product strategy for non-technological innovation, such as modeling, operation, color, texture, attached materials and other sensory images, in the later period of the development. Figure 2.shows that on the market, it lacks of machines that are using time long and good ability at the same time.

\section{G. Questionnaire}

The questionnaire, collected anonymously in the form of randomly distributed to who have the willing to answer, mainly is to understand about the situations and habits when using the vacuum cleaners in the general family. The questionnaire is divided into three major projects: the first part is for understanding whether the respondents use the vacuum cleaner and like it or not, the second part, as the main content of the questionnaire, is to understand the habits of the respondents including the types of the vacuum cleaners, the average using time, the storage, etc., and the third part is 
respondent's profile.

A total of the valid questionnaires are 73, including 23 men, 50 women. 23 of them are students, 22 of them are housewives/househusbands, and 20 of them are office workers. 27 respondents do not have the of using the vacuum cleaner, so the study does more survey on the remaining 46 respondents.

The results show that most of them at home use the cord canister vacuum cleaners, and then cordless upright vacuum cleaner. Every using time is mostly within 30 minutes, and the result of the ability of the suction is enough. The weight when using is "It's ok." as the most and "Easy" and "Quite hard" as the same number of the responses. About the storage, there are $22.2 \%$ respondents consider their vacuum cleaners are easy to storage. After decomposing the vacuum cleaners, $35.6 \%$ of the respondents feel that they are easy to storage. $35.6 \%$ of respondents feel the vacuum cleaner are occupied, hard to storage. If the respondents want to buy a new vacuum cleaner, they would like to try the cordless upright vacuum cleaner $(51.1 \%)$, followed by the robot vacuum cleaner $(33.3 \%)$. Finally, the most common vacuum cleaner head is the floor head, $76.1 \%$. The results of the questionnaires show as Figures 3 to 11 .

Fig. 3. The gender percentages of the respondents.

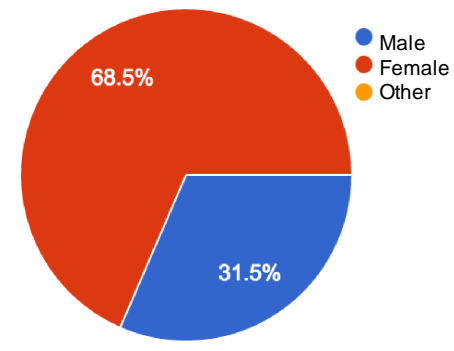

Fig. 4. The occupation percentages of the respondents.

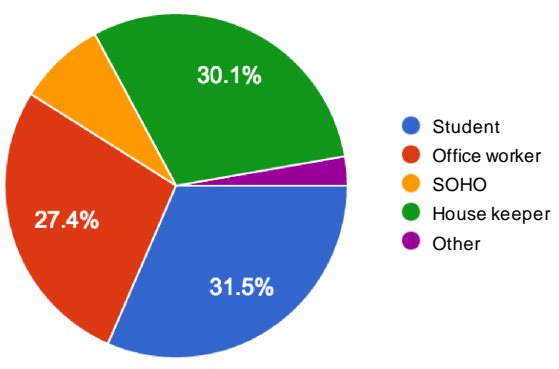

Fig. 5. The type of the vacuum cleaner at home. (Check all that apply.)

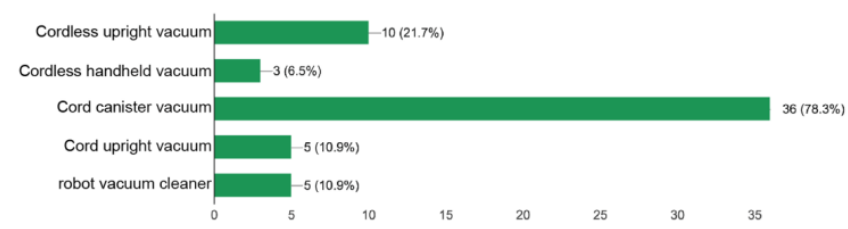

Fig. 6. The average time of using vacuum cleaner every time.

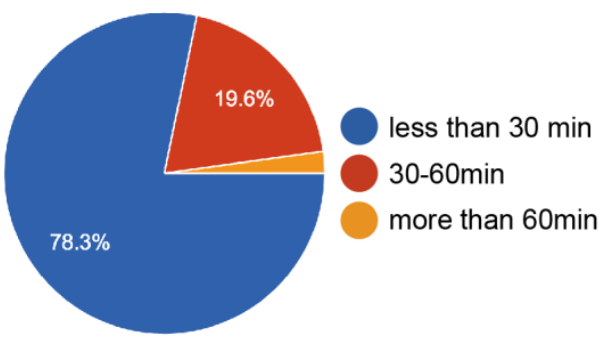

Fig. 7. Is the ability of vacuum enough?

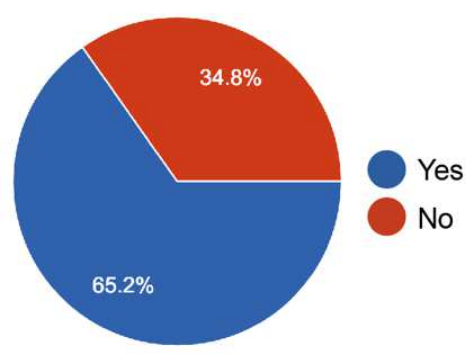

Fig. 8. The level of comfort when using.

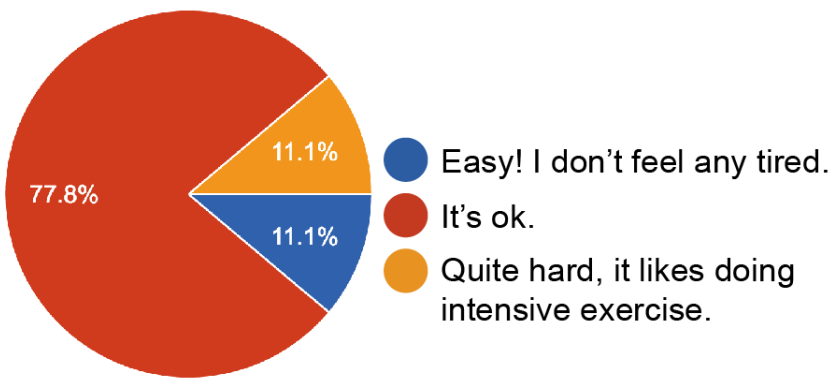

Fig. 9. The storage condition at home.

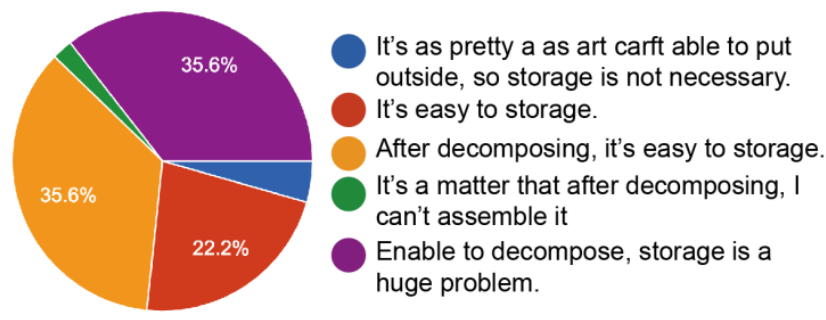

Fig. 10. If the respondents want to buy a new vacuum cleaner, what kind of the vacuum cleaner they would like to try. (Check all that apply)

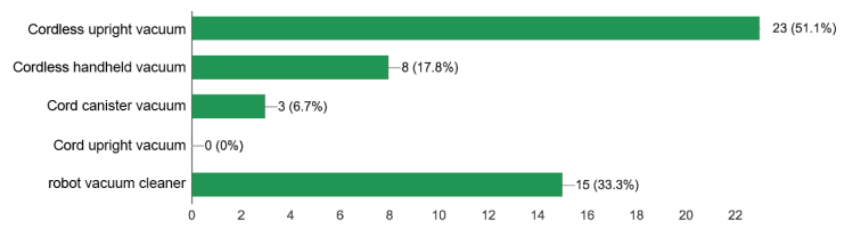


Fig. 11. Often-used vacuum cleaner head. (Check all that apply)

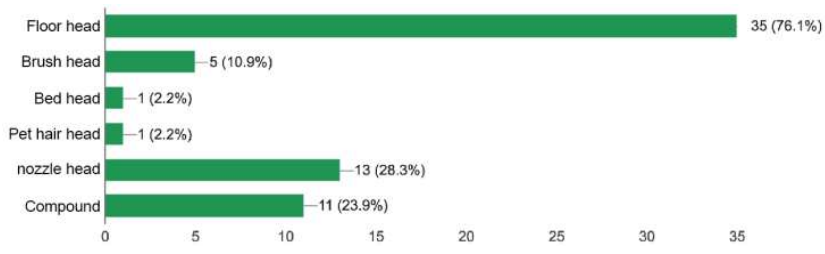

\section{H. Units}

In accordance with the previous surveys and questionnaires, through the $5 \mathrm{~W} 1 \mathrm{H}$, the black-box analysis and the tree diagram, set the main targets in the early design process. The design targets of this study are the following in accordance with $5 \mathrm{~W} 1 \mathrm{H}$ :

- WHO: household.

- WHEN: slight dust and scraps.

- WHERE: room, stairs, corridors.

- WHAT: the poor suction ability of the cordless vacuum cleaner and the difficulty to clean the filter.

- WHY: poor performance of the motor and entangled hair on head brush.

- HOW: adding or changing the devices.

Then analyze the using process with the black-box analysis to reflect the actual operation of the steps to predict the problems and difficulties that may occur when using. Also, diverge the ideas every aspect. This study will separate the using the vacuum cleaner and cleaning the vacuum cleaner because they are independent. The black-box process shows as Figure 12 and 13.

Fig. 12. The black-box analysis of using the vacuum cleaner.

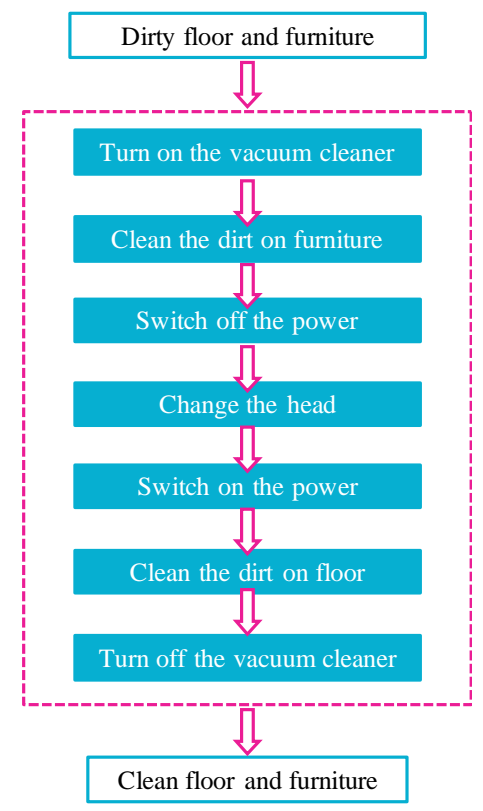

Fig. 13. The black-box analysis of cleaning the vacuum cleaner

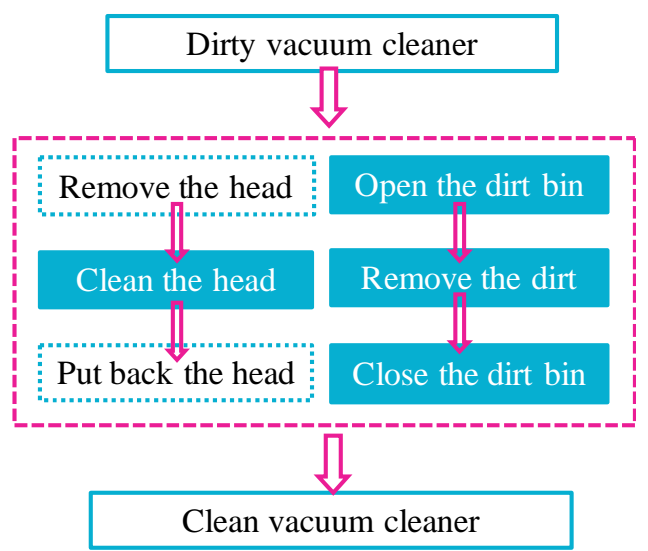

Based on the above analysis, it is able to set out the form and then set the demands, divided into the following:

- Demand: necessary function.

- Wish: non-essential function.

Bring demands/Wish into the design project, to draw the tree diagram of the targets, shown in Figure 14.

\section{The design process}

The study uses the morphological analysis and FSM analysis for the deconstruction of product functions and forms. As the basis of the developing the conception, the design process is shown as Figure 16, and the Figure 17 shows the function diagram.

\section{1) The product position}

The study categorizes the vacuum cleaner into five units: the motor unit, power unit, head unit, dirt bin unit and housing unit. First, remove the housing unit which should be designed based on all elements. The rest of four individually develop the details. Through the analysis and comparison, choose the most suitable solution from each unit, and then compose them together as the final decision. And the specifications are the best combination of the battery and the motor, HEPA filter, the volume of the dirt bin between 0.5 to $0.8 \mathrm{~L}$, using time between 45 to 60 minutes, the net weight less than $2 \mathrm{~kg}$, and volume less than $70 \mathrm{~dB}$. The design guidelines are having cleaning the head device, detachable dirt bin and filter, emergency stop button, exquisite appearance, and disassemble for storage.

\section{2) The overall shape develpoment}

Use FSM to vary the structure of the motor unit, the power unit, the dirt bin unit, and the head unit. After listing the all alternatives, remove the impossible structure and the rest of them will be analyzed on the following step, as Figure 18. (M represents the motor unit, $\mathrm{E}$ is the power unit, $\mathrm{C}$ represents the dirt bin unit, and $\mathrm{S}$ represents the head unit).

Use FSM to vary the position of the motor unit, the power unit, the dirt bin unit, and the head unit, shown as figure 19. ( $\mathrm{M}$ represents the motor unit, $\mathrm{E}$ is the power unit, $\mathrm{C}$ represents the dirt bin unit, and $\mathrm{S}$ represents the head unit). The pink square is the suitable alternative. 
Fig. 14. The tree diagram of the main targets.

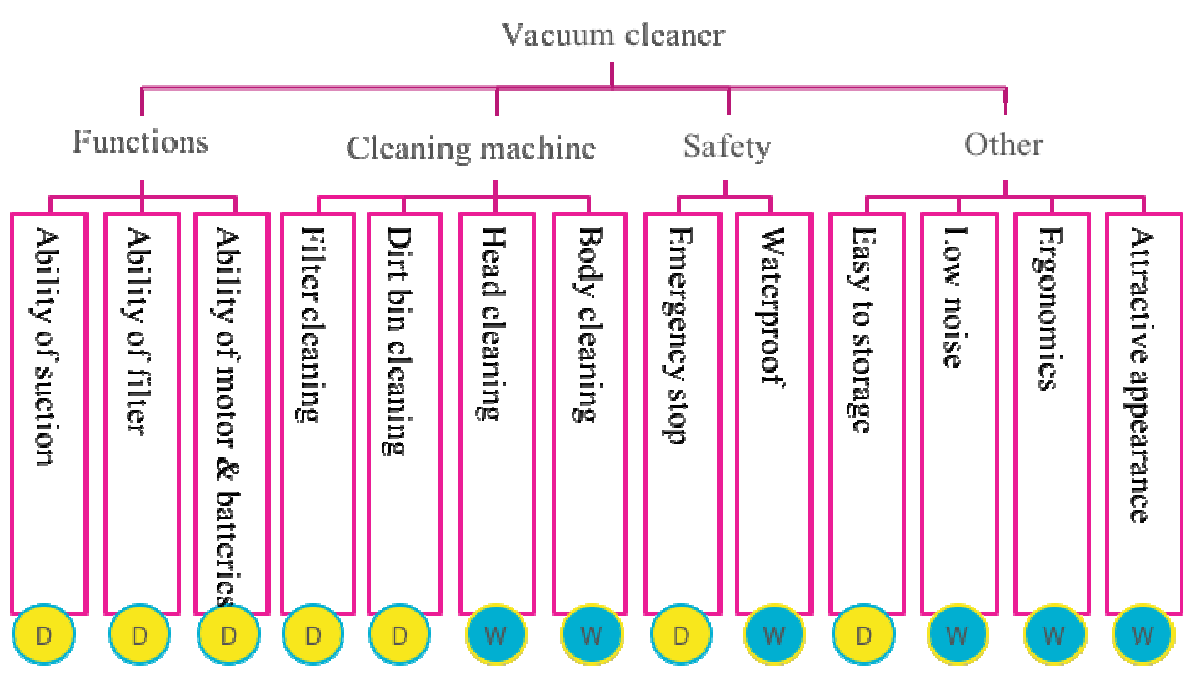

Fig. 15. The tree diagram of the detailed targets.

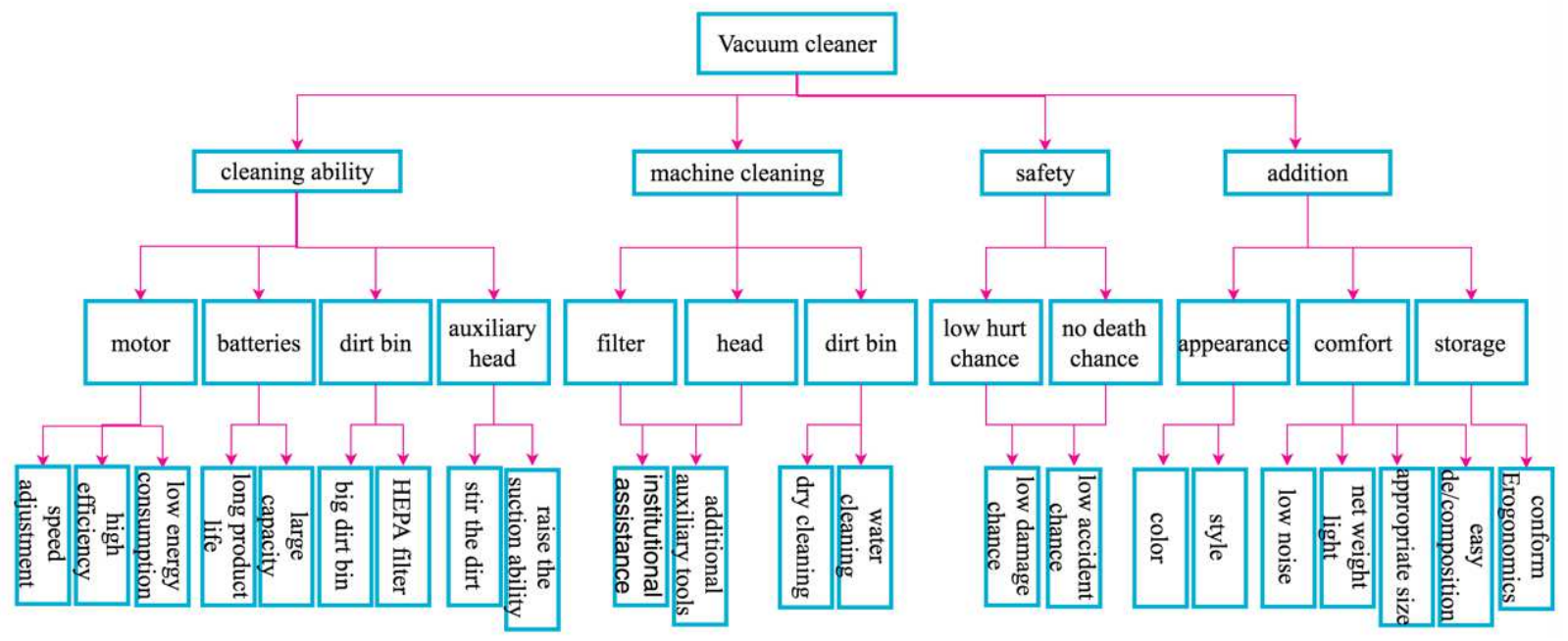

Fig. 16. The flow chart of the design process.

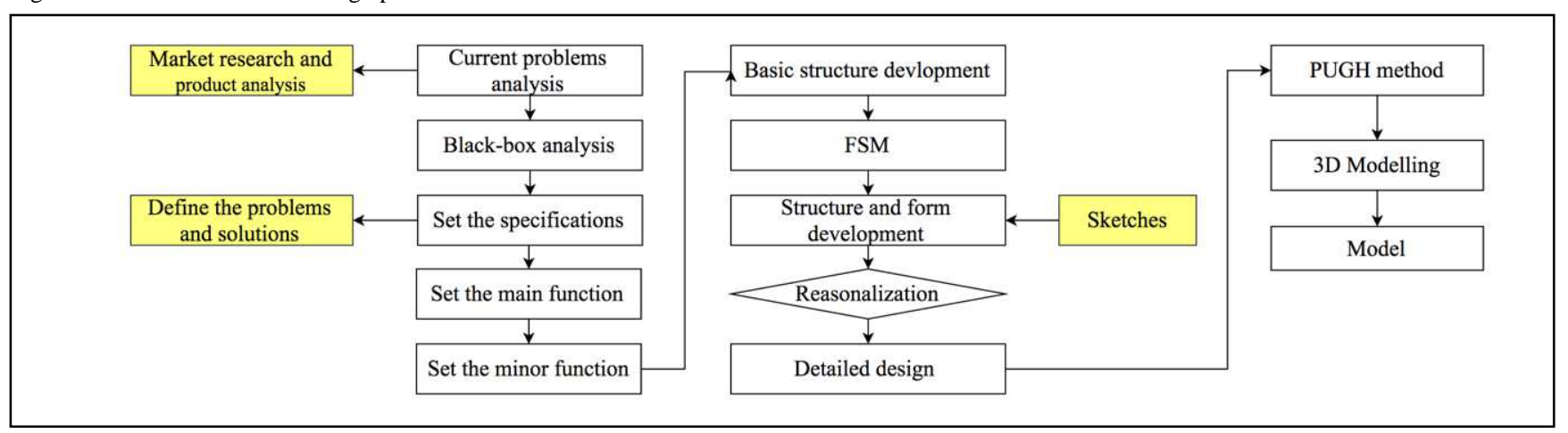


Fig. 17. The functional diagram.

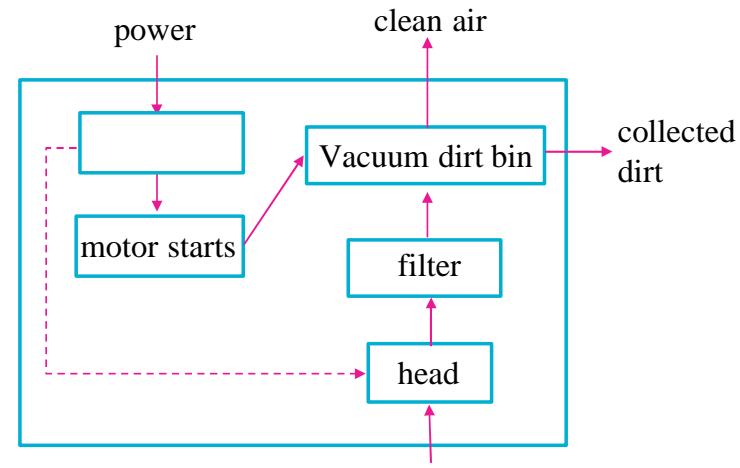

dirt on the floor

Fig. 18. The position analysis of the main functions on structure variables.
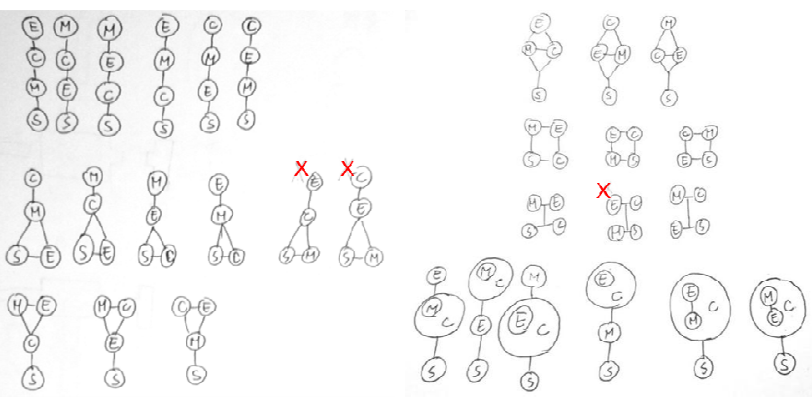

Fig. 19. The position analysis of the main functions on space variables.

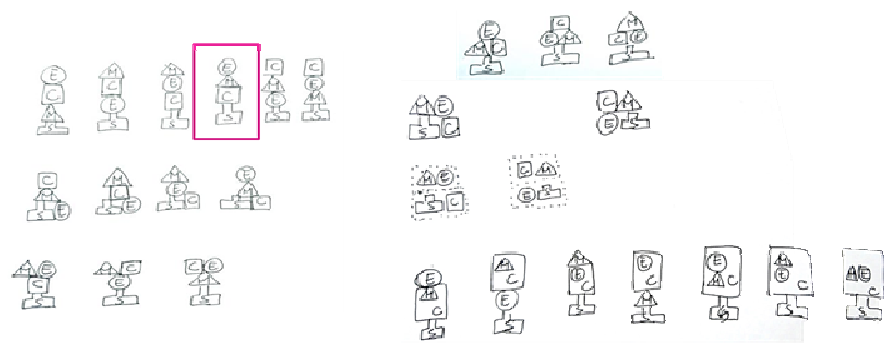

TABLE 3 THE MORPHOLOGICAL CHART OF THE FORM DEVELOPMENT.

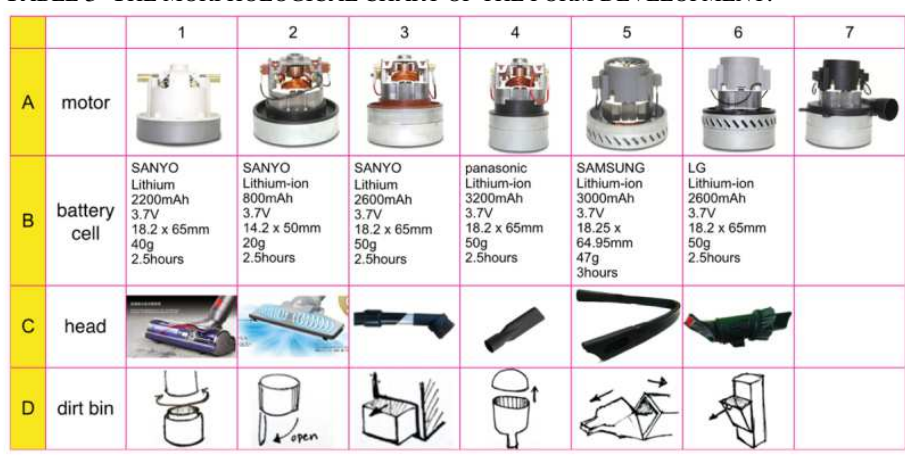

3) The form development

Since the products are not as works of the art craft, the product form should cooperate with the function and demands in order to rationalize the form. In this study, the morphological chart helps to reach the aesthetics, style, and innovative impression and also fits the functions. Its development shows in Table 3.

\section{4) The integration and ration}

After complete the form of each member unit development, it is necessary to integrate all the units in order to have a reasonable and practical design and also easy to manufacture. The motor unit and the power unit selected, do the preliminary classification of the appearance, shown as Figure 20. Then decompose the vacuum cleaner to design the details, shown as Figure 21, which presents eight alternatives. Third, use PUGH method to evaluate the idea. According to the results obtained after evaluating, do much more detailed design and planning, whose sketches shows as Figure 22-24. Finally, evaluate the alternatives by PUGH to get the best solution.

In the study, the forms have four categories: I simple upright, II gorgeous upright, III canister, and IV backpack.

In accordance with the assembling and convenience of using, propose two detailed design from each category.

\section{5) PUGH method and evaluation}

It is able to get the optimal design alternative from the former description of the eight alternatives after objectively evaluates by PUGH method, showing in Table 4.

The evaluated result is I-1 as the best design, but by table. 22, the scores II-1 and IV 1 are higher than the others. Hence, pick out and combine the advantages of these two alternatives (Fig. 22). Then evaluate detailed I-1 (Fig. 23) and II-2 (Fig. 24)and II+IV. The results show in Table 5. After evaluating by PUGH twice, I-1 is the optimal choice. Therefore, use I-1 to have $3 \mathrm{D}$ modeling.

\section{6) Modeling}

With the above evaluation, construct 3D model assembly to be simulated. Then, do the color plan to decide the color of the product, shown in Figure 26.

\section{RESULTS}

The product design is mainly for household cordless vacuum cleaner, which can clean the floor and the cabinets, window frames, desktop, etc. after replacing the different head. Meanwhile, solve the storage and the filter problems. The design, improved the shortcomings of the existing products, features:

- Simple appearance, suitable for all style of the decoration.

- The vacuum cleaner is easy to disassemble for storage.

- The cleaning operations of the filter and dirt bin are easy, which cleaned by water or dry cleaning after open them.

- The tube combines with the nozzle head to increase the ability of suction. It is hard to be disappeared by reducing a head when storage.

- The floor head with roller brush is attached a hair cleaning device, whose operation is easy.

- Reserve a soundproof space, reducing the sound of the motor operation, and users' unpleasant on physiology and psychology. 
Fig. 20. The categories of the form.

I

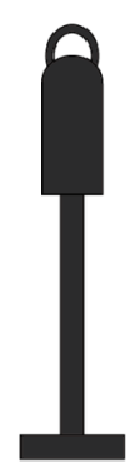

II

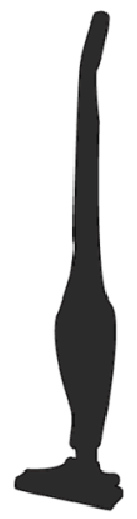

III

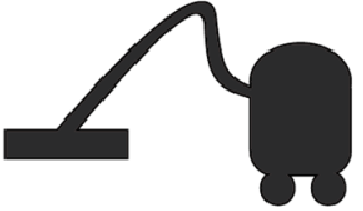

IV

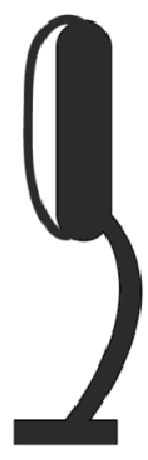

Fig. 21. Detailed design sketches.

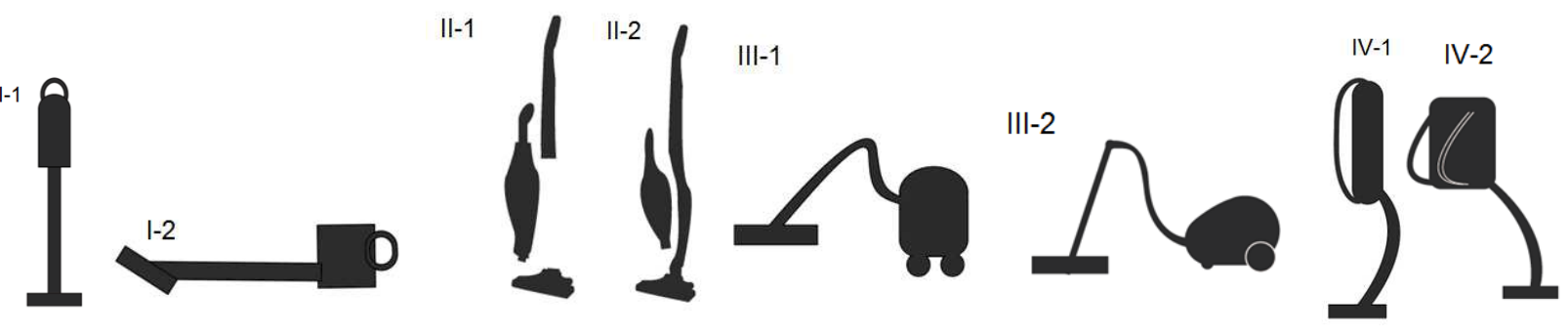

TABLE 4THE PRELIMINARY EVALUATION BY PUGH.

\begin{tabular}{|c|c|c|c|c|c|c|c|c|c|}
\hline Evaluation elements $\quad$ No. & $I-1$ & I- 2 & II -1 & II - 2 & III - 1 & III - 2 & IV -1 & IV-2 & weights \\
\hline $\begin{array}{r}\text { Is the dirt bin easy to clean or } \\
\text { not? }\end{array}$ & + & D & + & + & - & - & - & - & 5 \\
\hline $\begin{array}{r}\text { Is the filter easy to remove } \\
\text { and clean? }\end{array}$ & + & $A$ & + & + & $E$ & $E$ & + & + & 7 \\
\hline $\begin{array}{r}\text { Is the vacuum light or not } \\
\text { when using? }\end{array}$ & $E$ & $\mathrm{~T}$ & + & + & + & + & + & + & 3 \\
\hline $\begin{array}{r}\text { Is the vacuum noisy or not } \\
\text { when using? }\end{array}$ & - & U & - & - & + & + & + & + & 4 \\
\hline $\begin{array}{l}\text { Is the vacuum easy to } \\
\text { decompose or not? }\end{array}$ & + & M & $E$ & - & - & - & $E$ & - & 6 \\
\hline $\begin{array}{r}\text { Is the vacuum easy to storage } \\
\text { or not? }\end{array}$ & + & & $E$ & - & $E$ & - & $E$ & - & 6 \\
\hline+ score & 4 & & 3 & 3 & 2 & 2 & 3 & 3 & \\
\hline - score & -1 & & -1 & -3 & -2 & -3 & -1 & -3 & \\
\hline total score & 3 & & 2 & 0 & 0 & -1 & 2 & 0 & \\
\hline weighted score & 20 & & 11 & 1 & -4 & -3 & 9 & -3 & \\
\hline
\end{tabular}


TABLE 5THE SECONDARY EVALUATION BY PUGH METHOD.

\begin{tabular}{|c|c|c|c|c|c|}
\hline $\begin{array}{ll}\text { Evaluation elements } \quad \text { No. } \\
\end{array}$ & I- 1 & I - 2 & II+IV & weights & \\
\hline Is the dirt bin easy to clean or not? & ++ & + & ++ & 5 & \\
\hline Is the filter easy to remove and clean? & ++ & -- & $E$ & 7 & \\
\hline Is the vacuum light or not when using? & $E$ & - & ++ & 3 & \\
\hline Is the vacuum noisy or not when using? & + & ++ & + & 4 & \\
\hline Is the vacuum easy to decompose or not? & ++ & + & - & 6 & \\
\hline Is the vacuum easy to storage or not? & ++ & + & + & 6 & \\
\hline + score & 8 & 5 & 5 & & \\
\hline - score & 0 & -3 & -2 & & \\
\hline total score & 8 & 2 & 3 & & \\
\hline weighted score & 52 & 8 & 20 & & \\
\hline & & & & & $\begin{array}{r}\text { d. }++ \text { : much better, get }+2 \text { points. } \\
\text { e. }+ \text { : better, get } 1 \text { point. } \\
\text { f. E: equal, get } 0 \text { point. } \\
\text { g. } . \text { : worse, }-1 \text { point. } \\
\text { h. - -: much worse, get }-2 \text { points. }\end{array}$ \\
\hline
\end{tabular}

Fig. 22. Detailed design I-1.

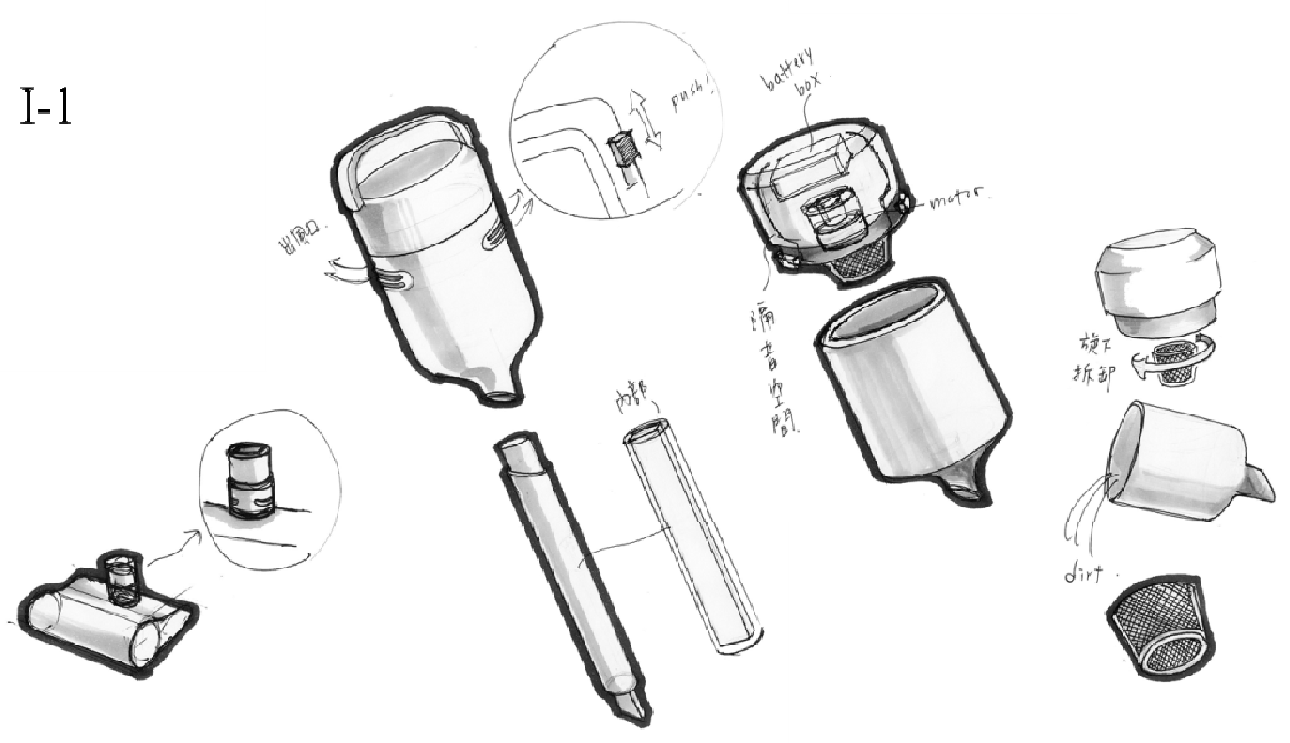


Fig. 23. Detailed design I-2.

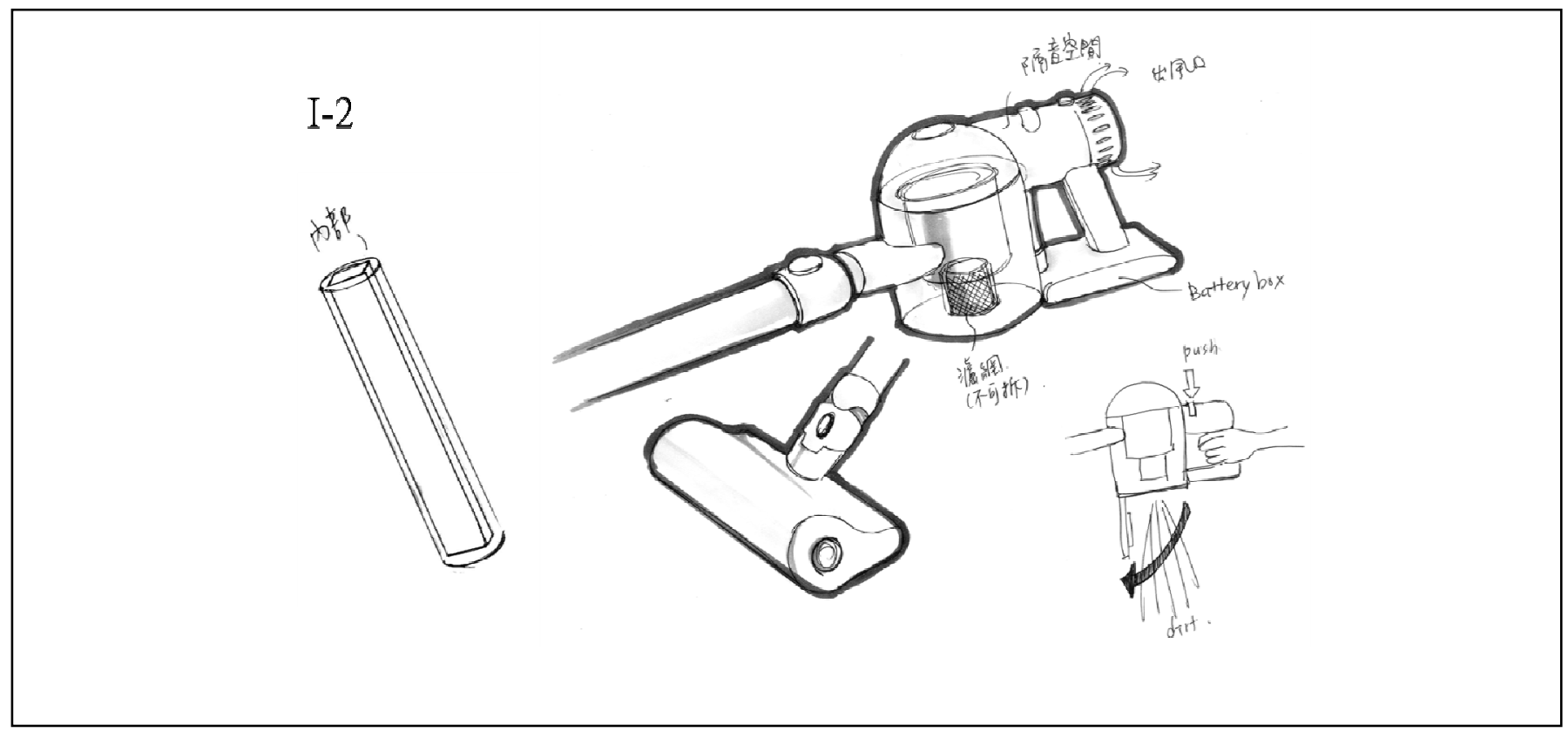

Fig. 24. Detailed design II+IV.
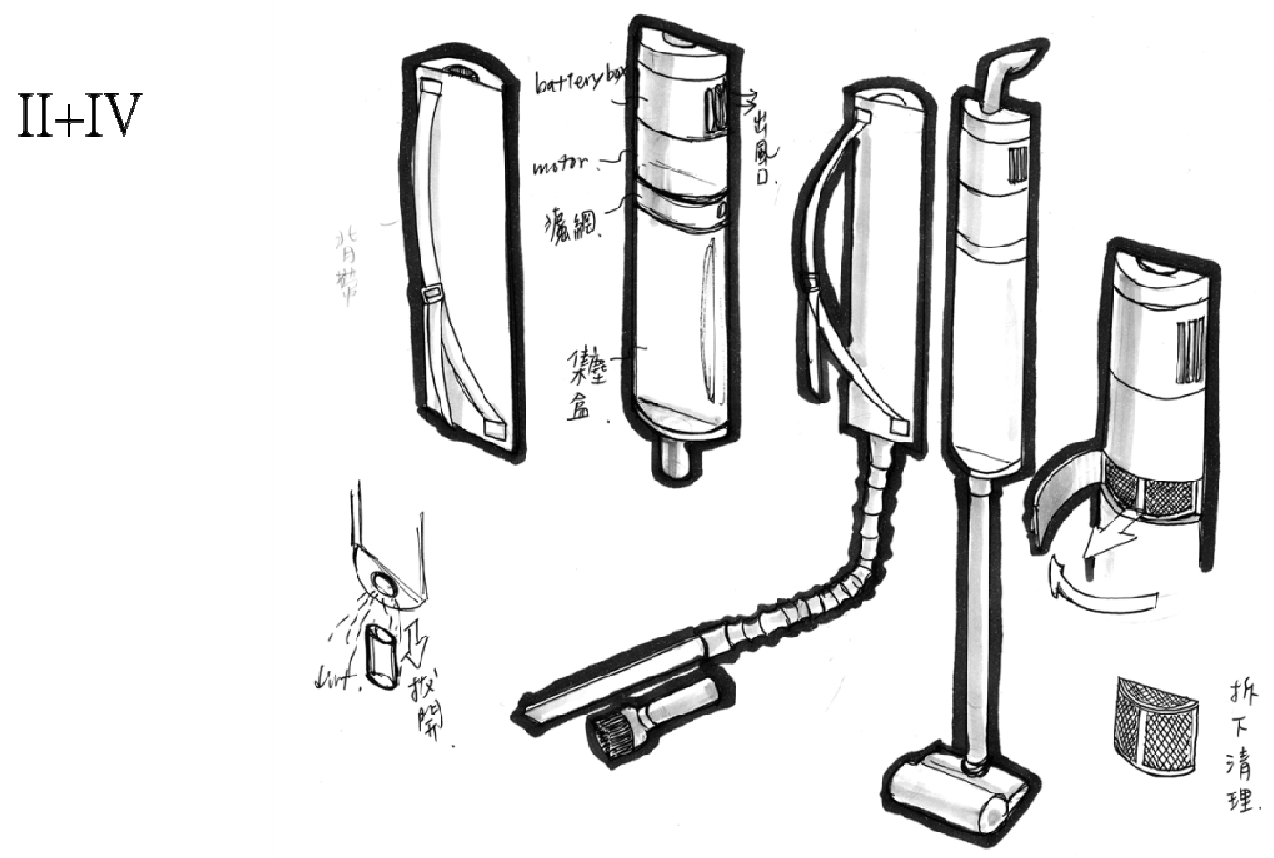
Fig. 25. The final product.

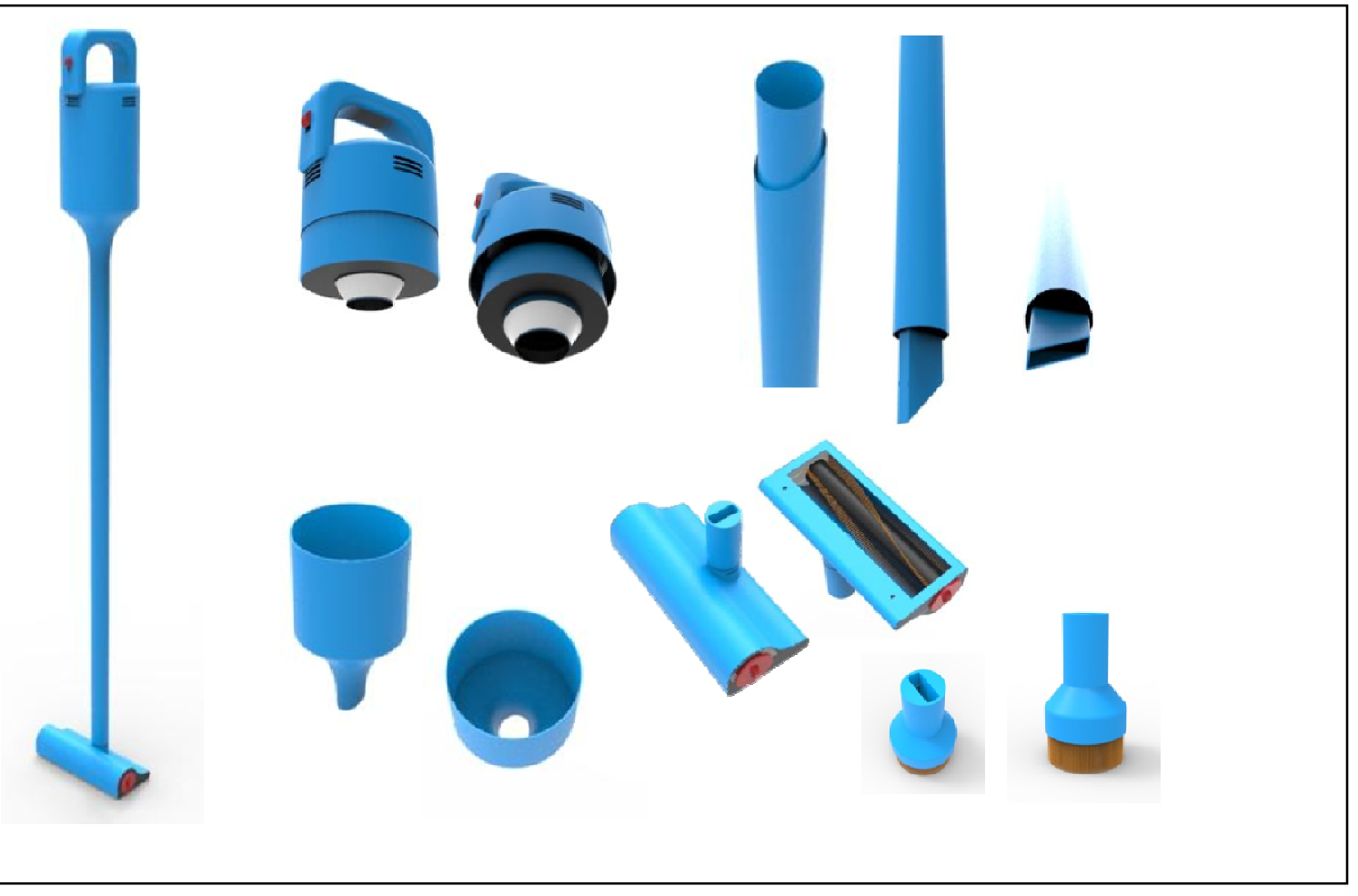

Fig. 26. The color plan of the cordless vacuum cleaner series.

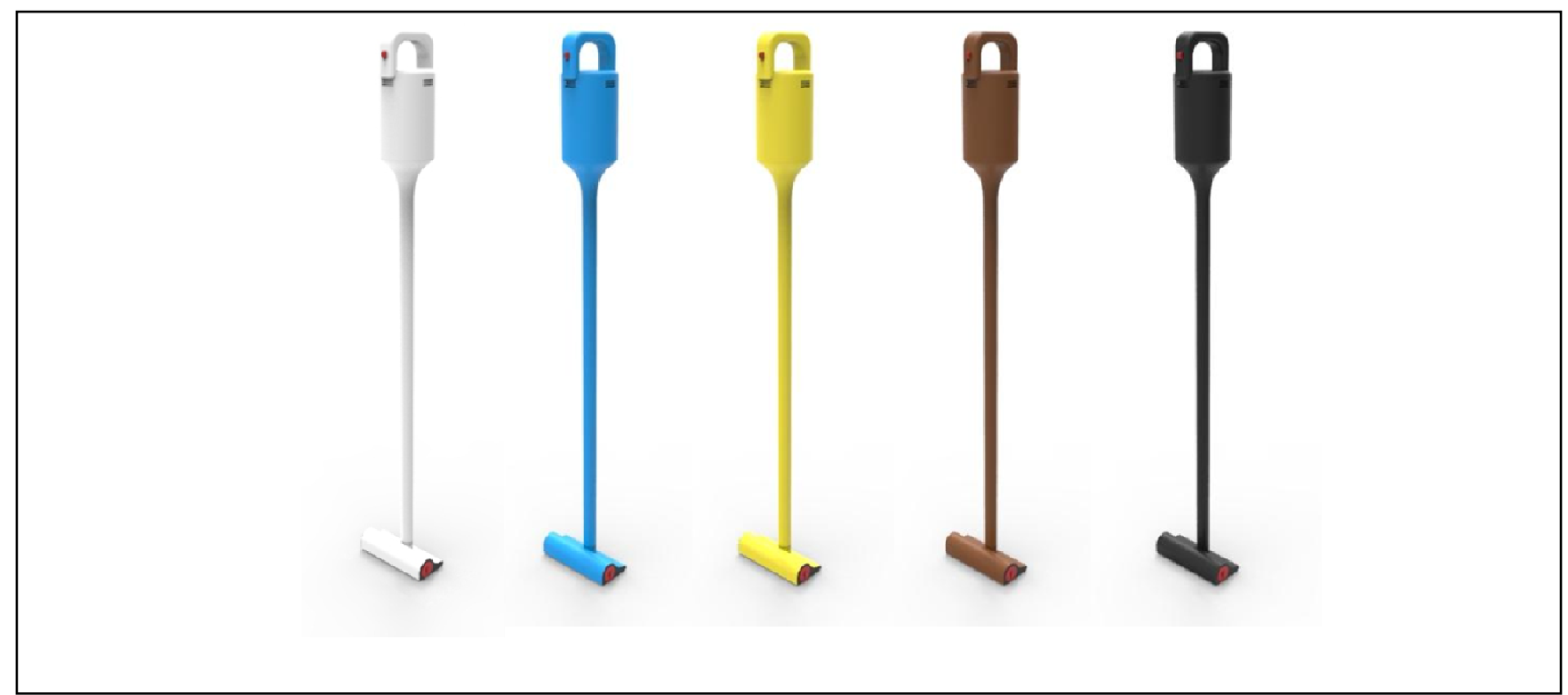

V. CONCLUSION

Designers often depend on personal perception, and experience to develop a product. When making a decision, it is lack of objective data and formula to prof that it is an optimal design. So a great success of a product depends on good luck or designer's abundant experience. The entire design process cannot clearly demonstrate to others, which results in failure to achieve substantial improvement. In this paper, the integration of a variety of design and analysis methods, 
including 5W1H, Morphological analysis, FSM, PUGH method, is used to develop a cordless vacuum cleaner, which not only meets the consumersdemands in function and aesthetics, but also reach the designer's expectations. Meanwhile, speed up the design process, and also to assist the designers clear the design goals, the core demand. The paper could make the analysis of production, and use more practical way to verify the feasibility of this approach. Even explore how to raise the quality, reduce production costs and increase the chance of more substantial products to quantify.

\section{References}

[1] Hsiao, S. W., 2002, Concurrent design method for developing a new product. International journal of Industrial Ergonomics, 29, 41-55.

[2] Lasswell, Harold Dwight, 1990, Politics Who Gets What, When and How, Peter Smith Pub Inc, the United States.

[3] Fritz Zwicky, 1967, The Morphological Approach to Discovery, Invention, Research and Construction, New Methods of Thought and Procedure, Section VI, pages 273-297.

[4] M. Garcarz, 2006, Lasswell, Harold Dwight, Encyclopedia of Language \& Linguistics (Second Edition), Elsevier Science, pages 703-705.

[5] Shih-Wen Hsiao, Cheng-Wei Fan, 1996, Integrated FSM, STM, and DFA Method on the Faucet Design, Journal of the Chinese Institute of Industrial Engineers, Vol 13, No. 3, Pages 225-235.

[6] Pugh. S. "Concept Selection - A Method That Works", Proceedings, International Conference on Engineering Design, (ICED 81), March 913, 1981.

[7] Ashafi'eMustafaa, MohdFadzli Bin Abdollaha, FairuzFazillahShuhimia, NurhidayahIsmaila, HilmiAmiruddina, NoritsuguUmeharac, 2015, Selection and verification of kenaffibres as an alternative friction material using Weighted Decision Matrix method, Materials \& Design, Volume 67, Pages 577-582.

[8] Good housekeeping website,

http://www.goodhousekeeping.com/home/cleaning/tips/g1098/vacuum cleaner-types-guide/? slide $=1$ 